\title{
Knowledge, Attitude, and Practice of Health Workers in a Tertiary Hospital in Ile-Ife, Nigeria, towards Ebola Viral Disease
}

\author{
Samuel Anu Olowookere, Emmanuel Akintunde Abioye-Kuteyi, \\ Olusegun Kayode Adepoju, Oluwaseun Taiwo Esan, Temitope Michael Adeolu, \\ Tolulope Kola Adeoye, Adesola Adebayo Adepoju, and Adedayo Titilayo Aderogba
}

Department of Community Health, College of Health Sciences, Obafemi Awolowo University, Ile-Ife, Nigeria

Correspondence should be addressed to Samuel Anu Olowookere; sanuolowookere@yahoo.com

Received 28 June 2015; Revised 21 September 2015; Accepted 4 October 2015

Academic Editor: Peter Leggat

Copyright (c) 2015 Samuel Anu Olowookere et al. This is an open access article distributed under the Creative Commons Attribution License, which permits unrestricted use, distribution, and reproduction in any medium, provided the original work is properly cited.

\begin{abstract}
Background. Health workers are more prone to Ebola viral disease (EVD) than the general population. This study assessed the preparedness of health workers in the control and management of EVD. Methods. A descriptive cross-sectional study. Consenting 400 health workers completed a semistructured questionnaire that assessed participants' general knowledge, emergency preparedness, and control and management of EVD. Data were analysed using descriptive and inferential statistics. Results. The mean age (SD) was $34.5 \pm 8.62$ years ranging from 20 to 59 years. Most participants were medical doctors (24.6\%) and nurses $(52.2 \%)$. The majority had practised $<10$ years $(73.8 \%)$ and were aware of the EVD outbreak in the West African subregion $(85.5 \%)$. Colleagues (40\%) and radio (37.2\%) were their major sources of information. Only $42 \%$ had good knowledge while $27 \%$ knew that there was no vaccine presently to prevent EVD. About one-quarter (24.2\%) had low risk perception. The majority (89\%) felt the hospital infection control policy was inadequate to protect against EVD. The only predictor of good knowledge was participants' occupation. Conclusion. There is knowledge gap and poor infection control preparedness among respondents. Thus, knowledge and practices of health workers towards EVD need improvement.
\end{abstract}

\section{Introduction}

Ebola viral disease (EVD) is an acute febrile illness caused by the Ebola virus, a member of the family of Filoviridae. EVD is associated with a high mortality rate in humans and nonhuman primates since its initial recognition in the Democratic Republic of the Congo in 1976 [1, 2]. The Filoviruses are thread-like RNA viruses that cause haemorrhagic fever. The Ebola virus causes severe disease in humans with an extremely high case fatality rate ranging from 25 to $90 \%$, depending on the viral subtype and the availability of medical care. Haemorrhagic symptoms occur in about $30-50 \%$ of described human cases [1]. Four Ebola viral subtypes (Zaire, Sudan, Ivory Coast, and Uganda) and the Marburg virus cause illness in humans, and the subtypes Zaire and Ivory Coast and the Marburg virus are known to cause illness in non-human primates. One Ebola subtype (Reston) causes illness in non-human primates but has induced only asymptomatic disease in humans [3]. The natural reservoir of the Ebola viruses remains unknown. The incubation period of Ebola virus is 2-21 days and it is transmitted majorly through direct contact with body fluid including blood, urine, excreta, vomit, saliva, sweat, mother's breast milk, organs, body parts, secretions, and seminal fluid. A rare mode of transmission is contact with the unknown natural reservoir or infected animals. Routes of infection are oral, the conjunctivae, mucousmembrane exposure (e.g., nose and mouth), sexual intercourse, and a break in the skin, a penetrating object infected with body fluids of a patient (e.g., needles or razor blades). Infections occur when health staff or relatives are taking care of a patient without proper protection. Contact with infected corpses (human or animal) put people at high risk to become 
infected with EVD. Nosocomial transmissions of EVD do occur when appropriate precautions are not taken [1].

The latest outbreak which affects Guinea, Liberia, Sierra Leone, and Nigeria in West Africa is the worst in EVD history with 2127 reported cases out of which 1145 died by August 15, 2014 [4]. Health workers were included among the infected and the dead from EVD while caring for people infected with this highly fatal disease. EVD prevention and control in the region raises a number of challenges for healthcare workers practising in countries where health systems and infrastructures are weak; healthcare financing is poor and health insurance coverage is limited [5]. Very few studies on EVD had been conducted among health workers in Nigeria [6]. It is therefore imperative to assess the preparedness of health workers in the control and management of EVD.

\section{Methods}

The study was conducted at the Obafemi Awolowo University Teaching Hospital Complex (OAUTHC), Ile-Ife, Nigeria, in the month of July, 2014. It is a 576-bedded hospital with referrals from neighbouring states such as Oyo, Ondo, Ekiti, Kogi, Kwara, and beyond.

The study population included the clinical members of staff, namely, medical doctors, nurses, pharmacists, medical laboratory technologists, community health workers (CHEW), medical records officer, and physiotherapists.

The sample size of 352 was calculated using an appropriate statistical formula for estimating the minimum sample size in descriptive health studies $\left[n=Z^{2} p q / d^{2}\right]$ [7], where $64.4 \%$ of health care workers knew that EVD had no cure [8]. A sample size of 400 was used after nonresponders being taken into consideration.

The number allocated to each group of clinical staff was determined proportionately using the formula $n / N \times 400$, where $n$ is the number of occupational groups and $N$ is the total number of clinical staff [9].

Consenting health workers completed a pretested semistructured self-administered questionnaire that assessed participants' general knowledge, emergency preparedness, and control and management of EVD. The questionnaires were distributed consecutively to members of each occupational group during the break period. The respondents were allowed to fill the questionnaire in their spare time at their convenience. Questionnaire information was anonymised.

Ethical approval to conduct the study was obtained from Ife Central Local Government Ethical Review Committee. Written informed consent was taken from the respondents while they were reassured of the confidentiality of the information obtained. The data collected were entered and kept in a password protected computer.

The data obtained were analysed using SPSS version 16. Simple descriptive and inferential statistics were done. Knowledge score was computed for a 41-item question on knowledge of EVD. Each item was assigned " +1 ” for correct knowledge and " 0 " for incorrect knowledge. The knowledge score was graded as good or appropriate (if respondent scored $\geq 27$ points) and not good or not appropriate (if score was $<27$ points) using the mean score as the break-off point. Test
TABLE 1: Sociodemographic characteristics of participants.

\begin{tabular}{lcc}
\hline Variable & Frequency & $\%$ \\
\hline Age group (years) & & \\
$20-29$ & 135 & 33.8 \\
$30-39$ & 164 & 41 \\
$\geq 40$ & 101 & 25.2 \\
Sex & & \\
Male & 159 & 39.8 \\
Female & 241 & 60.2 \\
Marital status & & \\
Single & 137 & 34.2 \\
Married & 263 & 65.8 \\
Occupation & & \\
Medical doctor & 98 & 24.6 \\
Nurse & 209 & 52.2 \\
Pharmacist & 25 & 6.3 \\
Medical laboratory technologist & 23 & 5.8 \\
Community health officers & 19 & 4.7 \\
Medical records officer & 17 & 4.2 \\
Physiotherapist & 9 & 2.2 \\
Duration of employment (years) & & \\
$<10$ & 295 & 26.8 \\
$\geq 10$ & 105 & \\
\hline
\end{tabular}

of significance was conducted using appropriate statistical methods. Multivariate analysis was performed using logistic regression to evaluate sociodemographic variables and other variables that are independently associated with good knowledge of EVD. Adjusted odd ratio (AOR) and 95\% CI were presented and used as measures of the strength of association. Significant level was put at $p<0.05$.

\section{Results}

Four hundred completed questionnaires were analysed. The mean age $(\mathrm{SD})$ of the respondents was $34.5 \pm 8.62$ years (range 20-59 years). Most participants were medical doctors $(24.6 \%)$ and nurses $(52.2 \%)$. The majority were females $(60.2 \%)$, were married $(65.8 \%)$, and had practised $<10$ years $(73.8 \%)$ (Table 1).

The majority $342(85.5 \%)$ were aware of the on-going EVD outbreak in the West African subregion. Colleagues (40\%) and radio (37.2\%) were their major sources of information (Table 2).

Only $42.3 \%$ had good knowledge of EVD (Figure 1). Most knew that EVD is a viral infection (93.2\%) that is deadly (91.5\%). Also, majority knew that EVD can be transmitted from person to person $(87.8 \%)$ and animal to person $(86.2 \%)$ while only $46.8 \%$ knew it can be transmitted from inanimate objects to persons (Table 3 ).

Although the majority of participants knew that EVD is transmissible through body fluids, below half knew that the causative agent penetrates broken skin (Table 4).

Most health workers knew high grade fever (78.2\%) and unexplained bleeding (73.4\%) as common presentation 
TABLE 2: EVD awareness and source of information on the outbreak.

\begin{tabular}{lcc}
\hline Variable & Frequency & $\%$ \\
\hline Aware of EVD epidemic in West Africa & & \\
$\quad$ Yes & 342 & 85.5 \\
No & 58 & 14.5 \\
${ }^{*}$ Source of information & & \\
Colleagues & 160 & 40.0 \\
Radio & 149 & 37.2 \\
Internet & 114 & 28.4 \\
Television & 93 & 23.3 \\
Newspapers & 92 & 23.1 \\
Notice boards/pamphlets & 44 & 10.9 \\
\hline
\end{tabular}

${ }^{*}$ Multiple responses.

TABLE 3: EVD knowledge of clinical variables.

\begin{tabular}{|c|c|c|}
\hline Variable & Frequency & $\%$ \\
\hline \multicolumn{3}{|c|}{ Ebola fever is a viral disease } \\
\hline Yes & 373 & 93.2 \\
\hline No & 27 & 6.8 \\
\hline \multicolumn{3}{|c|}{$\begin{array}{l}\text { Incubation period last from } 2 \text { to } 21 \\
\text { days }\end{array}$} \\
\hline Yes & 247 & 61.8 \\
\hline No & 153 & 38.2 \\
\hline \multicolumn{3}{|c|}{ The reservoir is usually bats } \\
\hline Yes & 270 & 67.5 \\
\hline No & 130 & 32.5 \\
\hline \multicolumn{3}{|c|}{$\begin{array}{l}\text { Infection with the organism is usually } \\
\text { deadly }\end{array}$} \\
\hline Yes & 366 & 91.5 \\
\hline No & 34 & 8.5 \\
\hline \multicolumn{3}{|c|}{$\begin{array}{l}\text { Ebola can be transmitted from person } \\
\text { to person }\end{array}$} \\
\hline Yes & 351 & 87.8 \\
\hline No & 49 & 12.2 \\
\hline \multicolumn{3}{|c|}{$\begin{array}{l}\text { Ebola can be transmitted from animal } \\
\text { to person }\end{array}$} \\
\hline Yes & 345 & 86.2 \\
\hline No & 55 & 13.8 \\
\hline \multicolumn{3}{|c|}{$\begin{array}{l}\text { Ebola can be transmitted from } \\
\text { inanimate objects to person }\end{array}$} \\
\hline Yes & 187 & 46.8 \\
\hline No & 213 & 53.2 \\
\hline
\end{tabular}

in EVD patients while fewer health workers knew that gastrointestinal symptoms and shock (27\%) could occur in these patients (Table 5).

Although majority of participants knew some treatment and prevention of EVD, about three-quarter did not know that EVD has no vaccine presently (Table 6). Most respondents were not aware of the process for EVD reporting (Table 7). Most respondents had poor risk perception and negative attitude to EVD diagnosis, management, and prevention. About $11 \%$ felt that the infection control policy of the
TABLE 4: Knowledge of EVD mode of transmission.

\begin{tabular}{lcc}
\hline Variable & Frequency & $\%$ \\
\hline $\begin{array}{l}\text { Ebola can be transmitted through } \\
\text { saliva }\end{array}$ & & \\
$\quad$ Yes & 274 & 68.5 \\
$\quad$ No & 126 & 31.5 \\
Ebola can be transmitted through & & \\
blood & & \\
$\quad$ Yes & 331 & 82.8 \\
$\quad$ No & 69 & 17.2 \\
Ebola can be transmitted through & & \\
seminal/vagina fluid & & \\
$\quad$ Yes & 222 & 55.5 \\
$\quad$ No & 178 & 44.5 \\
Causative agent penetrates broken skin & & \\
$\quad$ Yes & 186 & 46.5 \\
$\quad$ No & 214 & 53.5 \\
Bodies of dead cases constitute a \\
potential hazard \\
$\quad$ Yes \\
No \\
$\begin{array}{l}\text { Cases cease to be infectious after the } \\
\text { acute phase of the disease }\end{array}$ \\
$\quad$ Yes \\
$\quad$ No
\end{tabular}

TABLE 5: Knowledge of EVD clinical presentation.

EVD cases are characterized by fever $>38^{\circ} \mathrm{C}$

$\begin{array}{lcc}\text { Yes } & 313 & 78.2 \\ \text { No } & 87 & 21.8\end{array}$

Unexplained bleeding could be diagnostic

$\begin{array}{lll}\text { Yes } & 294 & 73.4 \\ \text { No } & 106 & 26.6\end{array}$

Vomiting, diarrhoea, and shock are rarely observed in

hospitalized patients

$\begin{array}{lll}\text { Yes } & 292 & 73.0 \\ \text { No } & 108 & 27.0\end{array}$

Fever refractory to treatment and unexplained mucosal bleeding is a sign

$\begin{array}{lll}\text { Yes } & 296 & 74.0\end{array}$

$\begin{array}{lll}\text { No } & 104 & 26.0\end{array}$

hospital is adequate to protect health workers against EVD (Table 8).

Medical doctors (54.1\%) and nurses (42.6\%) had appropriate knowledge compared to other health workers and this association was statistically significant (Table 9).

The only predictor of good/appropriate knowledge was participants' occupation (Table 10). 
TABLE 6: EVD knowledge of treatment and prevention.

\begin{tabular}{|c|c|c|}
\hline Variable & Frequency & $\%$ \\
\hline \multicolumn{3}{|c|}{${ }^{*}$ Drug use for treatment } \\
\hline Antipyretics & 343 & 85.8 \\
\hline IV fluids & 339 & 84.8 \\
\hline Corticosteroids & 212 & 53.0 \\
\hline \multicolumn{3}{|c|}{$\begin{array}{l}\text { Uses of vaccine protect from } \\
\text { EVD infection }\end{array}$} \\
\hline Yes & 292 & 73.0 \\
\hline No & 108 & 27.0 \\
\hline \multicolumn{3}{|c|}{$\begin{array}{l}\text { Environmental sanitation } \\
\text { protects from infection }\end{array}$} \\
\hline Yes & 350 & 87.5 \\
\hline No & 50 & 12.5 \\
\hline \multicolumn{3}{|c|}{ Safe sex protects from infection } \\
\hline Yes & 248 & 62.0 \\
\hline No & 152 & 38.0 \\
\hline \multicolumn{3}{|c|}{$\begin{array}{l}\text { Barrier nursing protects from } \\
\text { infection }\end{array}$} \\
\hline Yes & 333 & 83.2 \\
\hline No & 67 & 16.8 \\
\hline \multicolumn{3}{|c|}{$\begin{array}{l}\text { Cases can be confirmed without } \\
\text { laboratory assistance }\end{array}$} \\
\hline Yes & 125 & 31.2 \\
\hline No & 275 & 68.8 \\
\hline
\end{tabular}

TABLE 7: Knowledge of EVD reporting.

\begin{tabular}{lcc}
\hline Variable & Frequency & $\%$ \\
\hline Critical number of cases must & & \\
occur before reporting & 174 & 43.5 \\
$\quad$ True & 150 & 37.5 \\
$\quad$ False & 76 & 19.0 \\
$\quad$ Not sure & & \\
Suspected cases qualify for & & \\
reporting & 322 & 80.5 \\
$\quad$ True & 20 & 5.0 \\
$\quad$ False & 58 & 14.5 \\
$\quad$ Not sure & & \\
Cases should be reported weekly & & \\
for administrative efficiency & 227 & 56.8 \\
$\quad$ True & 67 & 16.8 \\
False & 106 & 26.4 \\
Not sure & & \\
Tertiary health facilities should & & 72.5 \\
notify directly & 290 & 52.8 \\
Federal ministry of health & 211 & 52.0 \\
State ministry of health & 208 & \\
Local ministry of health & & \\
\hline
\end{tabular}

${ }^{*}$ Multiple responses.
TABLE 8: Risk perception and attitude to EVD.

\begin{tabular}{lcc}
\hline Variable & Frequency & $\%$ \\
\hline Consider self to be at risk & & \\
Agree & 156 & 39.0 \\
Disagree & 173 & 42.8 \\
Undecided & 71 & 18.2
\end{tabular}

Health workers are prone to having EVD

$\begin{array}{lcc}\text { Agree } & 303 & 75.8 \\ \text { Disagree } & 51 & 12.7 \\ \text { Undecided } & 46 & 11.5\end{array}$

It is possible to prevent EVD spread

$\begin{array}{lcc}\text { Agree } & 318 & 79.5 \\ \text { Disagree } & 35 & 8.7 \\ \text { Undecided } & 47 & 11.8\end{array}$

There is no risk in living with EVD patient

$\begin{array}{lcc}\text { Agree } & 20 & 5.0 \\ \text { Disagree } & 332 & 83.0 \\ \text { Undecided } & 48 & 12.0\end{array}$

Infection control policy of the hospital is inadequate

\begin{tabular}{lcc} 
Agree & 109 & 27.3 \\
Disagree & 42 & 10.5 \\
Undecided & 249 & 62.2 \\
\hline
\end{tabular}

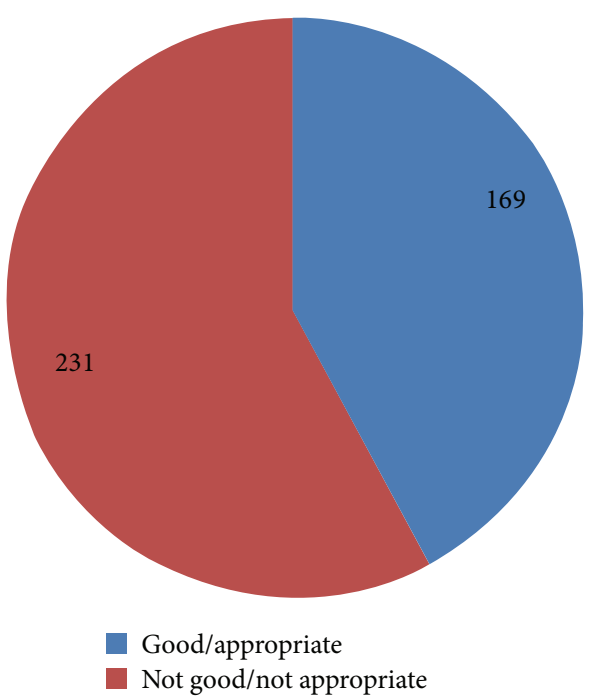

FIGURE 1: Graded score on EVD knowledge.

\section{Discussion}

This study assessed the knowledge, attitude, and practice of health workers in a tertiary hospital in the south-western part of Nigeria towards EVD. The health workers that participated included medical doctors, nurses, pharmacists, medical 
TABLE 9: Association between respondents' characteristics and knowledge of EVD.

\begin{tabular}{|c|c|c|c|c|}
\hline \multirow{2}{*}{ Variable } & \multicolumn{2}{|c|}{ Knowledge } & \multirow{2}{*}{$\chi^{2}$} & \multirow{2}{*}{$p$ value } \\
\hline & Appropriate & Not appropriate & & \\
\hline \multicolumn{5}{|l|}{$\overline{\text { Age (years) }}$} \\
\hline $20-29$ & $58(43.0)$ & $77(57.0)$ & \multirow{3}{*}{5.720} & \multirow{3}{*}{0.057} \\
\hline $30-39$ & $78(47.6)$ & $86(52.4)$ & & \\
\hline$\geq 40$ & $33(32.7)$ & $68(67.3)$ & & \\
\hline \multicolumn{5}{|l|}{ Sex } \\
\hline Male & $70(44.0)$ & $89(56.0)$ & \multirow{2}{*}{0.341} & \multirow{2}{*}{0.559} \\
\hline Female & $99(41.1)$ & $142(58.9)$ & & \\
\hline \multicolumn{5}{|l|}{ Marital status } \\
\hline Currently married & $111(42.2)$ & $152(57.8)$ & \multirow{2}{*}{0.001} & \multirow{2}{*}{0.980} \\
\hline Not currently married & $58(42.3)$ & $79(57.7)$ & & \\
\hline \multicolumn{5}{|l|}{ Occupation } \\
\hline Medical doctor & $53(54.1)$ & $45(45.9)$ & \multirow{3}{*}{12.291} & \multirow{3}{*}{0.002} \\
\hline Nurse & $89(42.6)$ & $120(57.4)$ & & \\
\hline Other health workers & $27(29.0)$ & $66(71.0)$ & & \\
\hline \multicolumn{5}{|c|}{ Duration of employment (years) } \\
\hline$<10$ & $132(44.7)$ & $163(55.3)$ & \multirow{2}{*}{2.869} & \multirow{2}{*}{0.090} \\
\hline$\geq 10$ & $37(35.2)$ & $68(64.8)$ & & \\
\hline
\end{tabular}

TABLE 10: Binary logistic regression of respondents' characteristics and EVD knowledge.

\begin{tabular}{lccc}
\hline Variable & AOR & $95 \%$ CI & $p$ value \\
\hline Occupation & & & \\
$\quad$ Medical doctor & 2.879 & $1.582-5.239$ & 0.001 \\
Nurse & 1.813 & $1.072-3.065$ & 0.026 \\
Other health workers (ref.) & 1 & & \\
\hline
\end{tabular}

laboratory technologists, medical record officers, physiotherapists, and community health workers. All these health workers come into contact with patients or their body fluids in the work place. Hence this baseline study determines their preparedness towards EVD. Most participants were young, were females, were married, and had practised less than 10 years. This implies that the participants still had more years to work and hence the necessity to remain healthy in order to perform their health care duties. Also, these health workers could be a source of spread of this life threatening infection to coworkers, their families, and community.

Although most respondents were aware of the EVD epidemic in the West African subregion, some were not aware. This is not acceptable as every health worker should be aware to ensure necessary precautions are taken to reduce the ongoing epidemic and control it whenever such spreads to the facility. This will ensure early diagnosis, management, control, and reporting of such cases to appropriate authority whenever they occur. Colleagues and radio were identified by the participants as their major sources of information. This shows the importance of peers and media in information management. Studies in Nigeria and elsewhere had reported the radio as a valid means of spreading current information to hospital workers as well as the general populace $[8,9]$.
Over half of the respondents had poor knowledge of EVD. This is probably because as at the time this study commenced, no case was reported in Nigeria. EVD was seen by most respondents as too far away to be a problem. However, this perception about a dangerous infectious disease such as EVD could result in uncontrollable epidemics; hence attitudinal change will be necessary if this must be averted. The World Health Organization had reported several cases of EVD outside the epidemic zone with Nigeria reporting its first case on July 20, 2014 [10]. This study reported that most respondents knew that EVD is caused by a deadly virus while they did not know it can penetrate broken skin. Also, most respondents did not know that EVD has no vaccine presently and were not aware of the process for EVD reporting. This shows the gap in knowledge that must be filled urgently.

Most participants felt that the infection control policy of the hospital was inadequate to protect health workers against EVD. This implies that the hospital authorities must do all that is required to develop a policy targeting EVD.

Occupation was found to be the only predictor of EVD knowledge with medical doctors and nurses having better knowledge more than other health workers. This reflects the training undergone by these groups of workers and the need to strengthen the capacity of other health workers with adequate knowledge of preventing, diagnosing, and managing EVD cases. All health workers need continuous education on EVD. Also, the training should focus on the concept of universal precautions, which must be observed by every health care worker while interacting with every patient [11].

This baseline study is limited by its cross-sectional design and the fact that some respondents could have given socially acceptable answers to some questions. However, this study will serve as a guide for planning and implementing interventions targeted at controlling possible epidemics in the study area. 


\section{Conclusion}

In conclusion, most health workers had inappropriate knowledge about EVD; hence continuous medical education focusing on the concept of universal precautions should target all health workers. Also, an infection control policy targeting EVD is urgently required and emergency preparedness towards possible EVD epidemic is necessary.

\section{Conflict of Interests}

The authors declare that they had no competing interests.

\section{Acknowledgments}

The authors are grateful to the management of Obafemi Awolowo University Teaching Hospitals and health workers that participated in this study. The authors thank Mr. Anthony Adejuwon for editing this paper.

\section{References}

[1] E. Sterk, MSF Ebola \& Marburg Outbreak Control Guidance Manual, 2008.

[2] C. Comoro and J. Sivalon, "Ebola: fear of the unknown," Tanzania Health Research Bulletin, vol. 3, no. 2, pp. 1-4, 2001.

[3] J. Changalucha, "EBOLA: haemorrhagic fever outbreak in Uganda: the Mwanza region experience," Tanzania Journal of Health Research, vol. 3, no. 2, pp. 4-6, 2001.

[4] World Health Organization, Global Alert and Response (GAR): Ebola Virus Disease Update-West Africa, 2014, http://www .who.int/csr/don/2014_08_15_ebola/en/.

[5] A. Yakubu, M. O. Folayan, N. Sani-Gwarzo, P. Nguku, K. Peterson, and B. Brown, "The Ebola outbreak in Western Africa: ethical obligations for care," Journal of Medical Ethics, 2014.

[6] Center for Public Policy Alternatives, Study on the Ebola Virus Disease (EVD) Knowledge, Attitudes and Practices of Nigerians in Lagos State, Center for Public Policy Alternatives, 2014.

[7] L. Kish, Survey Sampling, John Wiley \& Sons, New York, NY, USA, 1965.

[8] V. S. Cozma, Attitudes and Practices (KAP) Survey on the Ebola Virus Disease (EVD)_Kailahun and Kenema Districts, Sierra Leone, International Federation of Red Cross and Red Crescent Societies, Geneva, Switzerland, 2014.

[9] O. Adekanle, D. A. Ndububa, S. A. Olowookere, O. Ijarotimi, and K. T. Ijadunola, "Knowledge of hepatitis B virus infection, immunization with hepatitis B vaccine, risk perception, and challenges to control hepatitis among hospital workers in a Nigerian Tertiary Hospital," Hepatitis Research and Treatment, vol. 2015, Article ID 439867, 6 pages, 2015.

[10] D. Grady, "With Ebola cases still few, populous Nigeria has chance to halt its outbreak," The New York Times, 2014, http://nyti .ms/1mSQTu2.

[11] S. A. Olowookere, A. A. Fatiregun, O. O. Gbolahan, and E. G. Adepoju, "Diagnostic proficiency and reporting of Lassa fever by physicians in Osun State of Nigeria," BMC Infectious Diseases, vol. 14, article 344, 8 pages, 2014. 


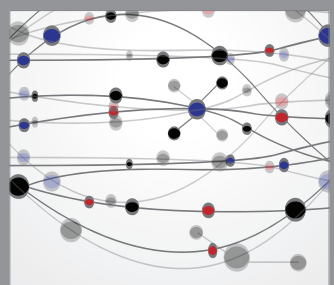

The Scientific World Journal
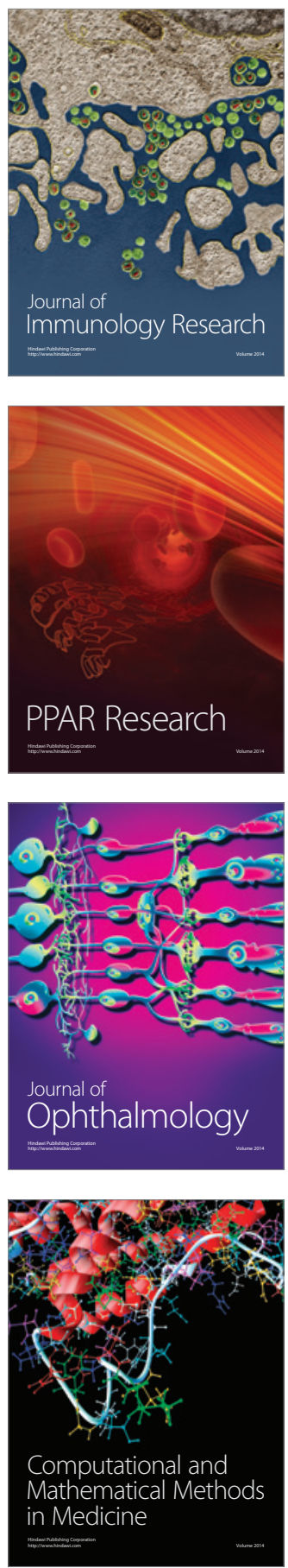

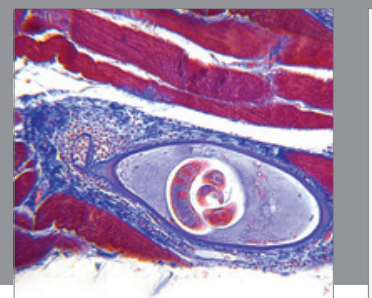

Gastroenterology

Research and Practice
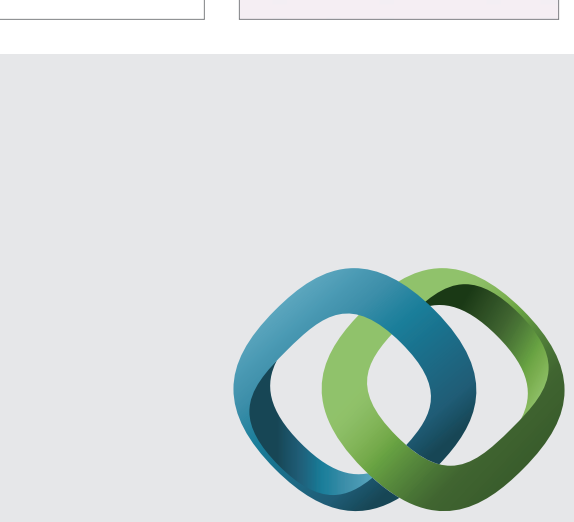

\section{Hindawi}

Submit your manuscripts at

http://www.hindawi.com
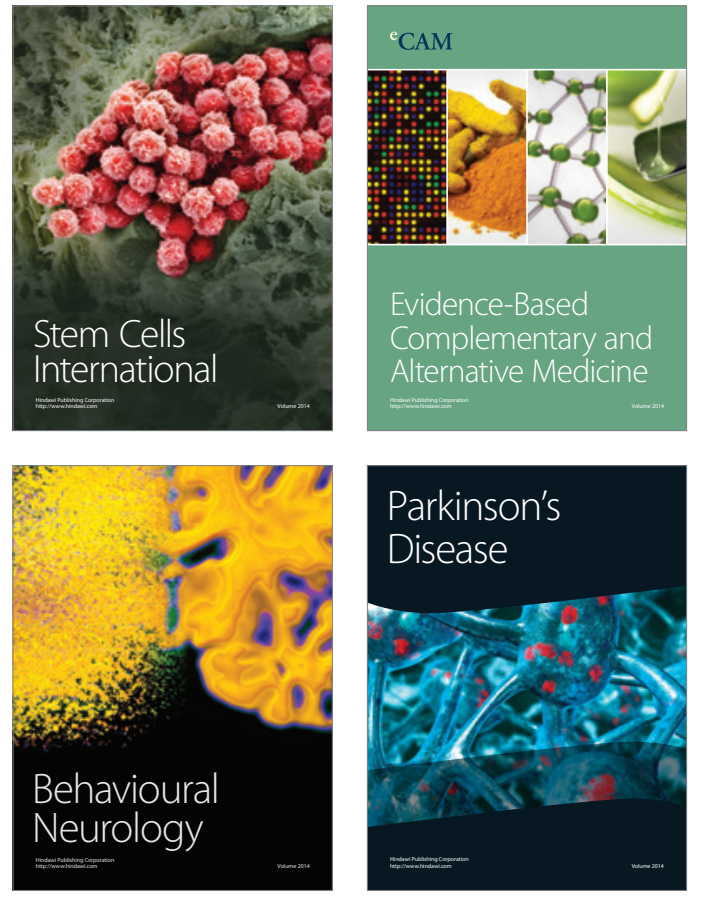
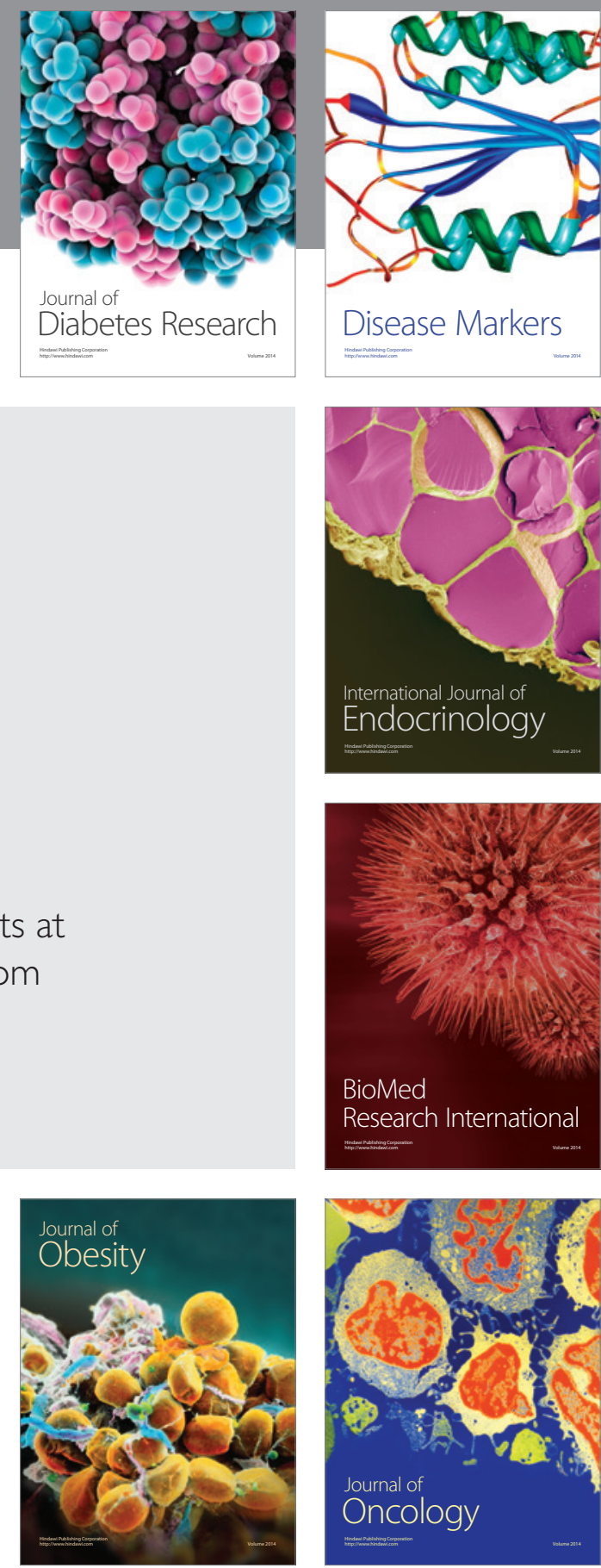

Disease Markers
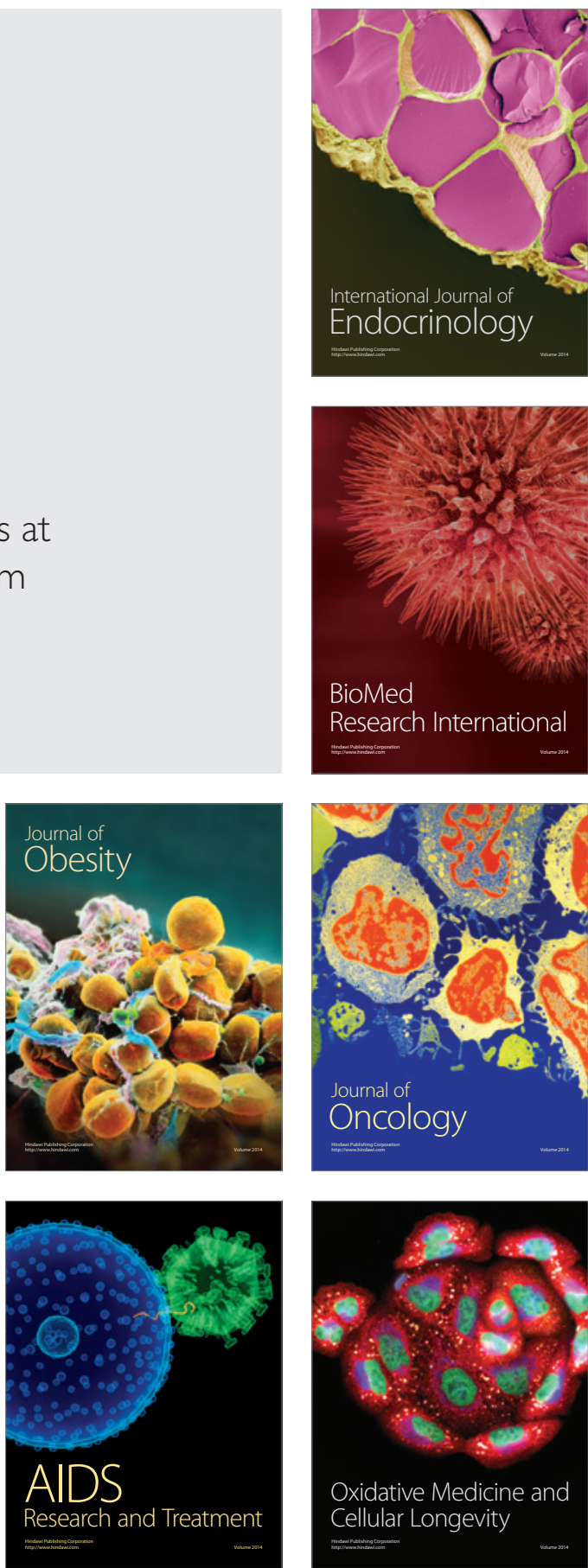